\title{
TAKING THE "CROSS” \\ OUT OF CROSS-CULTURAL TRANSFER OF MANAGEMENT PRACTICE
}

David Stephen

Professor at the University of Colorado at Denver (USA).

E-mail: diverseworkforce@usa.net

\section{RESUMO}

Organizações multinacionais freqüentemente tentam replicar práticas de gestão de sucesso em contextos

"estrangeiros". No entanto, essas práticas podem ser etnocêntricas porque se adequam a suposições, comportamentos e valores do ambiente cultural original. A menos que os pressupostos subjacentes sejam compartilhados, a transferência para um contexto diferente pode fracassar. Ainda que o foco seja mudado das diferenças culturais para a implementação, as abordagens de implementação podem ser também criticadas como etnocêntricas pelas mesmas razões. Neste artigo, um modelo não-etnocêntrico é expandido e utilizado para testar a capacidade de transferência de uma prática gerencial, a avaliação de desempenho, dos Estados

Unidos para o Brasil. Esse "Teste de Capacidade de Transferência" pode auxiliar gerentes a entender quais práticas são transferíveis e, talvez, até de forma mais valiosa, fornecer um critério para adaptação ou rejeição.

\section{ABSTRACT}

Multi-national enterprises often attempt to replicate successful management practices in "foreign" environments. However, such practices may be ethnocentric because they fit the assumptions, behaviors, expectations, and values of the home cultural environment. Unless the underlying assumptions are shared, transfer to a differing environment may fail. Even if the focus is shifted from cultural differences to implementation, implementation approaches may also be criticized as ethnocentric for the same reasons. In this article, a non-ethnocentric model is expanded and used to test the portability of one management practice, performance appraisal, from the USA to Brazil. This "Test of Portability" may help managers understand which management practices are portable, and, perhaps even more valuable, provide a rationale for adaptation or rejection.

\section{PALAVRAS-CHAVE}

Gestão intercultural, avaliação de desempenho, recursos humanos, etnocentrismo, antropofagia.

\section{KEY WORDS}

Cross-cultural management, performance appraisal, human resources, ethnocentrism, anthropophagia. 


\section{INTRODUCTION}

As organizations "internationalize", that is, as they move outside of the domestic environment, crossing international borders to find new markets and new resources, they often seek to implement their management practices in familiar ways, using methods, processes and procedures which are perceived to have previously contributed to success domestically (Daniels and Radebaugh, 1998). This includes transferring Human Resource Management (HRM) practices and policies to new cultural environments. Likewise, firms based outside the USA frequently attempt to import foreign management practices perceived to improve success (Wood Jr. and Caldas, 1998). Such cross-cultural transfer of management technology is problematic because many practices are culturally bound. But while virtually all authorities admit that national culture is a major influence on the sensible management of human systems, it is not at all clear which management practices transfer well from one culture to another, which do not, and why this is so.

The literature on HRM indicates that many concepts and management practices developed in the USA may be criticized as ethnocentric (Hollinshead and Leat, 1995; Clark, 1996; Mendenhall and Oddou, 1995). The management practices inherent in the American HRM model are supported by underlying American cultural assumptions, behaviors, expectations, and values. USA style HRM fits other national environments only to the degree that the underlying assumptions are shared. Even if the "culture variable" could be controlled in some way and the focus shifted to implementation, American style implementation approaches may also be criticized as ethnocentric for the same reasons. In this article, a nonethnocentric, anthropophagous approach (Wood Jr. and Caldas, 1998) is used to test the portability of the HR practice of performance appraisal from the USA to Brazil. The analysis provides an explanation of why transfer is successful or not, and the model used offers a process for deconstructing, then reassembling the practice, crafting it to fit the new environment.

\section{METHODOLOGY}

Human resource managers at 14 firms in Brazil were interviewed in July and August, 2000, using both a structured survey and open interview techniques. The primary research questions were: "What foreign management practices can be successfully transferred to Brazil? Which cannot? What adaptations are necessary, and how is adaptation accomplished?" The firms included nine multi-national enterprises (MNE's) with USAheadquarters management influence, three MNE's with
European influence, two Brazilian-run firms with some USA influence due to ownership or joint venture issues, and one exclusively Brazilian owned firm. Interviews were tape recorded, transcribed, and coded. Qualitative data analysis revealed that formal performance appraisal was a difficult procedure to implement in Brazil. In only one firm had performance appraisal for developmental and compensation purposes been implemented, and then for a narrowly targeted group of employees.

Respondents attributed the difficulty in transferring the practice of formal performance appraisal to two factors. First, face-to-face, objective criticism is less socially acceptable in Brazilian culture; informants expressed apprehension that such a direct approach might chill the warm social climate they believed to be

\section{Cross-Cultural tRANSFER OF \\ MANAGEMENT TECHNOLOGY IS PROBLEMATIC BECAUSE MANY} PRACTICES ARE CULTURALLY BOUND.

important in the workplace. Second, respondents described managers as unskilled at coaching and developing subordinates, and described employees at all levels as lacking a strong sense of responsibility for developing themselves professionally and taking control and ownership of their own careers. This generalization was attributed to the historical effects of extractive colonialism, social paternalism and hierarchy, and an unstable economic and political environment, which resulted in a general attitude that the locus of control is external to the individual. These specific observations are congruent with Hofstede's more general assessment of Brazilian culture, which shows a high tolerance for power inequalities, a mildly collectivist social orientation, and a propensity to avoid uncertainly (Hofstede, 1991). This is in sharp contrast to the USA scores on the same dimensions. In addition, Hall (1983) implies that Brazil employs a high context communication style while the USA is distinctly low in context. This would predict the observation that direct critiques of performance behaviors would be shunned in Brazil.

\section{PRELIMINARY FINDINGS}

To find that cultural differences are a variable in the transfer of management practices is not surprising. The managers we interviewed grasped this concept intuitively. What is surprising is that no managers felt they had either the freedom to change the management practice or an 
implementation approach in order to insure both an environmental fit and a productive outcome. This is somewhat ironic since the interview data also revealed that respondents describe Brazilian managers as creative, flexible, and skilled at improvising. Why were these attributes not employed when they were asked to transfer and adapt the performance appraisal process?

\section{TEST OF PORTABILITY FOR}

\section{PERFORMANCE APPRAISAL}

Formal performance appraisal is a management practice that was developed in the USA and has been a popular approach to performance improvement. Managers in other national settings have attempted to employ the appraisal process, with varying degrees of success (English language translations of Latin American studies on this issue are, sadly, not available to USA based researchers).

First, we present key elements of the performance appraisal process as detailed by the USA based Society for Human Resource Management (SHRM, 2000). Next, we analyze the cultural assumptions that underpin the practice of performance appraisal and that make it appropriate for the cultural environment of the USA. Key environmental forces and resources that contribute to the efficacy of the practice are also noted. Finally, we test the portability - its potential for transfer - to Brazil by analyzing similar and

Figure 1 - Test of Portability for transfer of management practices in five steps

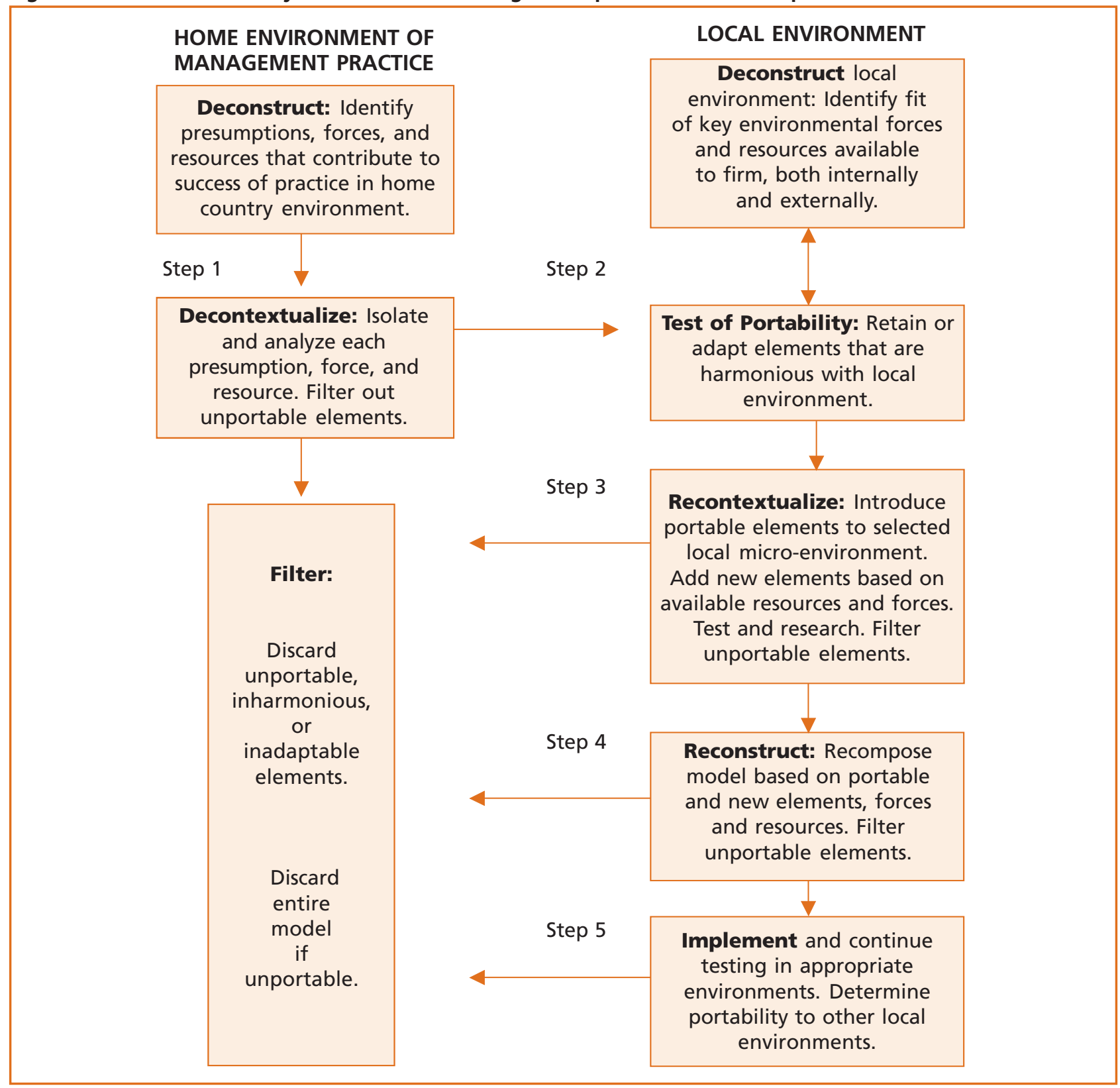


relevant cultural assumptions, external and internal forces, and resources in the Brazilian environment.

Stephen (2000) created a Test of Portability based on the model of organizational anthropophagia suggested by Wood Jr. and Caldas (1998). The model is illustrated in Figure 1. Organizational anthropophagia, or cannibalism, implies that a practice may not be simply adopted, but must be consumed, broken down, and metabolized by an organization. The process employs five steps:

a) Deconstruct the management model or practice and the environment which spawned it (in this case formal performance appraisal in the USA). Decontextualize, isolate, and analyze the environmental forces and resources that make the process valid and successful in the home environment.

b) Juxtapose these elements with the local environment (in this case Brazil), retaining, adapting, and filtering out unportable elements.

c) Recontextualize the portable and adapted elements by testing them in a local micro-environment that offers compatible forces and resources.

d) Reconstruct a model of the practice that fits the new environment using portable, adapted, and new elements spawned by local environmental forces and available resources.

e) Implement the management practice in appropriate local environments while continuing to test and monitor the long-term effects of both the model's validity and the success of the implementation process.

The Test of Portability is illustrated in Figure 1. The model allows for an assessment of portability at each step. The Test for Portability should indicate by Step 2 whether or not wholesale transfer is possible or extensive adaptation is necessary. Step 3 should provide some clear evidence of the degree of portability and need for adaptation in a micro-environment similar to the original. Reconstruction, in Step 4, should predict success or failure, pending the assessment of long-term results indicated in Step 5.

In the application below, we first present key elements of performance appraisal as detailed by SHRM (Figure 2), then we attempt to determine the portability of the process by applying the first three steps of the Test of Portability to Brazil (Figure 3). Finally, we suggest some managerial implications.

The SHRM process of performance appraisal is aimed at improving personal performance, and, by extension, the performance of the firm. However, we assert that what seems like a straightforward process is actually heavily burdened with cultural assumptions. Further, there are other environmental forces and resources available in the USA context that make this specific process uniquely

\section{Figure 2 - Performance appraisal: key points taken from SHRM}

\section{- During employee's first month}

Review organization's strategic plan or mission. Discuss department/division goals. Establish individual goals and action steps. Discuss expectations of quality and quantity of work, interpersonal skills, reliability and other performance factors typically reviewed.

\section{- After first three months}

Review individual goals and action steps. Review employee performance to date either formally or informally. Discuss formal performance evaluation process.

\section{- On a daily basis}

Note specific, job-related behaviors that are both positive and negative and keep for future reference. Immediately provide feedback on areas for improvement as problems occur. Openly praise positive behavior and good performance. Offer opportunities to discuss performance as issues arise.

\section{- Formal performance interview}

Choose a quiet, private spot with as few interruptions as possible. Create a positive environment and help the employee feel at ease. Give balanced feedback, both positive and negative, but start with the positive focus on the job, not the person. When discussing areas for improvement, discuss methods and objectives for improving. Discuss possibilities for advancement, the employee's aspirations and professional development necessary to be a candidate for such future positions. Have employee sign a written summary of the evaluation to acknowledge that he or she has read it (does not signify agreement with the content).

\section{- Pitfalls to avoid}

Avoid bias about an employee based on your personal feelings for that individual. Length of service or job grade does not necessarily mean better performance. Look carefully at the individual's performance within that job. Don't base current performance on past performance. Look at the current period being reviewed. Don't be afraid to provide truthful information. 
suited to the American environment.

Step 1 of the Test of Portability calls for analyzing the American environment, deconstructing the process of performance appraisal and decontextualizing the assumptions we identify. In Step 2, we proceed to analyze the relevant elements of the Brazilian environment and make a preliminary assessment of the portability of USA style performance appraisal when transferred to Brazil. Step 3 in the Test of Portability is to recontextualize the process. We identify an appropriate (hypothetical) Brazilian micro-environment that may accommodate portable elements and make adaptations to match that unique environment. We isolate actions that are not compatible with the environment and, if they cannot be adapted to fit, they are filtered out and discarded.

\section{Figure 3 - Test of Portability: transfer of performance appraisal to Brazil}

\section{Deconstruct and decontextualize home country (USA) presumptions:}

- The organization has reached a mature stage of organizational development and has a well developed mission statement and a clear strategic plan. Long-term planning is acceptable and appropriate in the relatively stable environment of the USA.

- Objective feedback is valued in order to assess performance, and is socially acceptable. Performance appraisal is face-to-face, one-on-one, frequent, consistent, permanent, and has long-term and short-term goals. Jobs are well defined and each individual's specific duties are clear.

- The professional relationship between employee and supervisor is more important on the job than their social relationship. Social relationships are separable from and subordinate to professional relationships.

- Employees should be accountable for their performance, and, by extension, the performance of the organization. Professional performance is quantifiable and performance should be tied to compensation and promotion.

- The importance of a formal, written, and signed performance appraisal reflects the employment-at-will practice of the USA, which relieves an employer of some post-employment liabilities if failure to meet performance standards can be documented. Length of service or position does not guarantee employment or affect dismissal.

- Managers are skilled at developing employees; they have coaching and teaching skills. People wish to improve performance for personal or professional reasons. Professional development initiatives are understood and embraced by workforce members, who also believe in the principal of self determination.

\section{Juxtapose with Brazilian environment. Retain portable and adaptable elements:}

- Brazilian managers may have limited experience with a commitment to long-term strategic planning due to a historically unstable environment. Some Brazilian firms are not yet mature enough to have developed a well defined mission and long-term goals.

- Objective, face-to-face feedback, may be perceived as a confrontational mode of communication and may be confused with social aggressiveness or tactlessness. Social relationships often take precedence over professional relationships in the Brazilian culture.

- Although quality and quantity of work may be similar in both environments, "interpersonal skills, reliability and other performance factors" may need to be redefined. Generally, employees should be accountable for their performance, and, by extension, the performance of the organization, but fear associated with an unstable economic and political environment make personal accountability risky, especially when tied to compensation and promotion. The unstable environment may also promote changing job functions so that specific duties are less clearly defined. Professional performance is quantifiable for some employees in some business functions, but not universal.

- Due to differing labor laws, formal, written, signed performance appraisals may not free the employer from post-employment liabilities in cases of dismissal, even if the employee fails to improve performance. Therefore the formal appraisal process carries less importance in the Brazilian legal environment.

- People wish to improve performance for personal or professional reasons, but professional development initiatives are not understood and embraced by all, and fatalism and paternalism serve to diminish a sense of self determination for some employees. Managers may not be skilled at developing themselves or subordinates on a day-by-day basis. Many in the workforce may perceive limits on potential advancement, whether such limits are real or only perceived.

Portability assessment: wholesale transfer not possible; extensive adaptation necessary; portability may be low. 
(continued)

\section{Recontextualize and introduce to a local micro-environment:}

- Identify a local population that might be receptive to formal performance appraisal (such as a sales force with clear, quantifiable goals).

- Select employees who are self-determined, and whose performance is not likely to be influenced by outside forces.

- Identify ways to implement appraisal metrics that do not abrade social relationships (such as measuring group performance or giving objective feedback via computer reports).

- Modify face-to-face feedback elements so they contribute to social cohesion rather than threaten conflict.

- Field test and research locally.

Portability assessment: depending on results in micro-environment, such extensive adaptations may render the practice ineffective.

\section{CONCLUSION AND MANAGERIAL IMPLICATIONS}

The Test of Portability offers new information for researchers and practitioners. First, it offers a thorough analysis of the cultural assumptions and environment that make performance appraisal successful in the USA (Step 1). Second, it helps identify potential environmental barriers to implementation (Step 2). Third, if transfer is attempted, it is advisable to identify an environment similar to the original and to reassemble the practice in ways that make it harmonious with the new environment (Step 3). This process provides evidence to determine whether portability problems are due to poor cultural fit or poor implementation procedures. If transfer fails for either reason, then at least we are rewarded with a better understanding of the portability issues, rather than dismissing the attempt by saying "We tried that and it doesn't work here because people don't like it".

Portability of management practices might be improved if the process of deconstruction, adaptation, and reconstruction were more accessible to managers. Accessibility could be improved by encouraging a crosscultural team to make the analyses indicated in Steps 1 and 2 , and by giving license to local managers of foreign MNE's to make the changes indicated in Steps 3 and 4.

The implication is that successful transfer is more likely when managers are free to analyze, adapt and change the practice, rather than attempting to force the implementation of an unportable practice. Even if the practice is discarded due to its unportability, the model offers a rationale for rejection that is somewhat more substantial than "It won't work here...". Finally, if it is true that Brazilians are creative, flexible, and skilled at improvising, then giving license to engage in Step 3 and 4 provides a stage on which to demonstrate these qualities. If a parallel, more appropriate model emerges in Step 4, then it would likely benefit the local operation and could also be portable enough to be exported to the home environment of the MNE as an improvement.

This theoretical piece needs additional validation. Psychologists skilled in cross-cultural testing in which tests are "reassembled" to retain construct validity in a differing cultural environment may be able to provide additional theoretical support for this model. Empirical studies to validate the process are essential. The goal of this article is simply to keep the idea current in the literature, and to present the perspective that "cross-cultural transfer of management practice" often involves a degree of ethnocentrism and managerial imperialism, while "testing for portability" and "cannibalizing management practices" imply a degree of respect which all "foreign" cultures deserve. Researchers who believe this idea has some merit are cordially invited to collaborate with the author to pursue this anthropophagous model of cultural portability. $\bigcirc$
REFERENCES
CLARK, T. European human resource management. Oxford : Blackwell, 1996.

DANIELS, J. D., RADEBAUGH, L. H. International business: environments and operations. New York: Addison-Wesley Longmont, 1998.

HALL, E. T. The silent language. New York : Anchor Books, 1983
HOFSTEDE, G. Culture and organizations: software of the mind. New York : McGraw-Hill, 1991.

HOLLINSHEAD, G., LEAT, M. Human resource management: an international and comparative perspective. London Financial Times-Pittman, 1995.

MENDENHALL, M., ODDOU, G. Readings \& cases in international human resource management. Cincinnati International Tomson, 1995.
SOCIETY FOR HUMAN RESOURCE MANAGEMENT. HR Basics 2000: Employee Performance. 2000. Available online: <www.shrm.org/whitepapers/basic/index.asp >.

STEPHEN, D. The transfer of human resource management practice to Brazil: a practical assessment and theoretical test of portability. Colorado State University, Ft. Collins, 2000. Unpublished doctoral dissertation.

WOOD JR., T., CALDAS, M. P. Antropofagia organizacional. RAE - Revista de Administração de Empresas, São Paulo, v. 38, n. 4, p. 6-17, out./dez. 1998. 